\title{
Detección Molecular de Estreptococos Cariogénicos en Saliva
}

\author{
Molecular Detection of Cariogenic Streptococci in Saliva \\ "Luis A. Salazar; ${ }^{* *}$ Claudio Vásquez; ${ }^{* *}$ Alejandro Almuna; ${ }^{* * *}$ Gonzalo Oporto; \\ **** Roberto Santana; ${ }^{* * * * * *}$ Christian L. Herrera \& ${ }^{* * * * *}$ Antonio Sanhueza
}

SALAZAR, L.A.; VÁSQUEZ, C.; ALMUNA, A.; OPORTO, G.; SANTANA, R.; HERRERA, C. L. \& SANHUEZA, A. Detección molecular de estreptococos cariogénicos en saliva. Int. J. Morphol., 26(4):951-958, 2008.

RESUMEN: Streptococcus mutans y Streptococcus sobrinus han sido indicados como los principales agentes etiológicos de la caries dental. Sin embargo, los métodos microbiológicos y bioquímicos, disponibles actualmente en Chile, no permiten la rápida detección e identificación de estas bacterias. El objetivo de este trabajo fue implementar la metodología de reacción en cadena de la polimerasa (PCR) para detectar la presencia de $S$. mutans y S. sobrinus en saliva. Participaron de este estudio 51 escolares (5 a 17 años), provenientes de cinco diferentes colegios de la ciudad de Temuco; a los cuales se les realizó recuento de estreptococos del grupo mutans en saliva por método microbiológico y la diferenciación de especies por la técnica de PCR. Los resultados mostraron que la sensibilidad para la técnica de PCR fue $1000 \mathrm{UFC} / \mathrm{mL}$ de saliva, diez veces superior a la sensibilidad del método microbiológico utilizado (10.000 UFC/mL). Además, el análisis de la especificidad de la amplificación, evaluada por restricción enzimática, confirmó la presencia de las bacterias investigadas. La prevalencia de $S$. mutans fue de $88.2 \%$ y para $S$. sobrinus de $11.8 \%$. La presencia conjunta de ambas bacterias fue observada en $7.8 \%$ de los individuos. En conclusión, podemos señalar que la metodología implementada es útil para la detección rápida de $S$. mutans y $S$. sobrinus en saliva.

PALABRAS CLAVE: Caries; Streptococcus mutans; PCR

\section{INTRODUCCIÓN}

La caries dental es la enfermedad crónica más prevalente a nivel mundial (Selwitz et al., 2007). En esta patología infecciosa, las bacterias estreptococos del grupo mutans, principalmente Streptococcus mutans y Streptococcus sobrinus, son las que se han asociado con mayor frecuencia al desarrollo de lesiones cariosas (Napimoga et al., 2005). Estos microorganismos juegan un rol vital en la patogenia de la caries, debido a su capacidad para favorecer la desmineralización del diente. Sin embargo, es importante recordar que esta patología es multifactorial e intervienen tanto factores personales como ambientales, dentro de los que destacan la susceptibilidad genética individual, las características del diente y la saliva, la dieta, los hábitos higiénicos, el nivel educacional, etc.

En los últimos años, se han desarrollado diversos mé- todos microbiológicos para poder detectar cepas de estreptococos con potencial cariogénico, estimando en algunos de ellos, además el número de Unidades Formadoras de Colonias (UFC) con el objetivo de monitorizar el grado de colonización de un individuo y establecer el riesgo de desarrollar caries dental desde el punto de vista microbiológico. Sin embargo, existen variaciones importantes en el porcentaje de recuperación de especies bacterianas dependiendo del medio de cultivo utilizado (Hildebrandt \& Bretz, 2006). Otras metodologías también usadas para lograr diferenciar especies bacterianas con potencial cariogénico, se basan en la morfología que presentan las colonias en agar, pruebas bioquímicas, inmunológicas y métodos genético-moleculares (Oho et al., 2000). Todas estas técnicas, si bien presentan buena sensibilidad y especificidad, en general tienen un costo económico elevado y/o son engorrosas en su realización.

\footnotetext{
Laboratorio de Biología Molecular \& Farmacogenética, Depto. de Ciencias Básicas, Fac. de Medicina, Universidad de La Frontera, Temuco, Chile. ** Alumnos Carrera de Tecnología Médica, Facultad de Medicina, Universidad de La Frontera, Temuco, Chile.

**** Alumnos Carrera de Odontología, Facultad de Medicina, Universidad de La Frontera, Temuco, Chile.

***** Depto. de Cs. Preclínicas, Fac. de Medicina, Universidad de La Frontera; Alumno Programa de Doctorado en Ciencias, mención Biología Celular y Molecular Aplicada, Universidad de La Frontera, Temuco, Chile.

******* Depto. de Matemáticas \& Estadísticas, Facultad de Ingeniería, Ciencias y Administración, Universidad de La Frontera, Temuco, Chile. Este trabajo fue financiado mediante los Proyectos: FONDEF de CONICYT N D05I10021 y DIDUFRO EP 120335, Dirección de Investigación y Desarrollo, Universidad de La Frontera, Temuco, Chile.
} 
Dentro de los métodos moleculares para la detección e identificación de microorganismos, los basados en la reacción en cadena de la polimerasa (PCR), surgen como una alternativa para realizar estudios epidemiológicos o bien en la clínica, debido a su elevada sensibilidad y especificidad, además de la rapidez a la hora de obtener resultados. En el caso de las bacterias estreptococos del grupo mutans se han utilizado con éxito diferentes genes que han permitido la identificación de especies bacterianas como son $S$. mutans y S. sobrinus (Aguilera \& Estrada, 2003; Igarashi et al., 2000; Sato et al., 2003).

En algunos de los estudios que involucran métodos moleculares, se ha utilizado como muestra clínica la placa dental, sin embargo, ésta no es la mejor muestra para la realización de estudios epidemiológicos debido a su difícil obtención, lo que a su vez dificulta el controlar la cantidad de muestra recuperada (Oho et al., 2000). Otros estudios han utilizado con éxito ADN cromosomal, el que es extraído mediante diferentes estrategias desde muestras de placa dental y saliva (Lindquist \& Emilson, 2004; Yano et al., 2002; Hoshino et al., 2004). Sin embargo, estos protocolos de extracción de ADN en ocasiones son laboriosos y requieren de la utilización de reactivos adicionales, con lo que aumenta el costo del examen.

Dado los antecedentes antes mencionados, el objetivo de este trabajo fue implementar la metodología de reacción en cadena de la polimerasa (PCR) para detectar la presencia de $S$. mutans y S. sobrinus directamente a partir de muestras de saliva.

\section{MATERIAL Y MÉTODO}

Sujetos. Se analizaron 51 escolares ( 29 varones y 22 mujeres) con edades entre 5 y 17 años, provenientes de 5 establecimientos educacionales de la ciudad de Temuco, Región de La Araucanía, Chile. Como criterio de exclusión se consideró el uso de antimicrobianos sistémicos o tópicos durante 15 días previos a la fecha de la toma de la muestra, y encontrarse bajo tratamiento con aparatos ortodoncicos fijos o removibles.

Todos los niños fueron sometidos a un examen clínico oral, donde se evaluó la historia de caries de acuerdo a los estándares OMS, mediante el índice COPD (dientes cariados, obturados y perdidos).

El protocolo de investigación utilizado en este estudio fue aprobado por el Comité de Ética de la Facultad de Medicina de la Universidad de La Frontera.
Muestras. La toma de las muestras de saliva se realizó según el método descrito por Linossier et al. (2003). Brevemente, las muestras se obtuvieron por estimulación de la secreción salival, utilizando un trozo de 0,9 gramos de parafina sólida durante 2 minutos, luego se solicitó a cada escolar que acumulara un volumen de saliva en el vestíbulo labial inferior que permitió sumergir una espátula plástica de 7,5 x 0,8 centímetros, inmediatamente cada espátula se colocó en el interior de un tubo estéril, que contenía medio de cultivo selectivo líquido TYCSB para el desarrollo de colonias de estreptococos del grupo mutans (caldo TYCSB, SOPROMED S. A., Santiago, Chile). Luego, se les solicitó depositar la saliva acumulada en un tubo estéril para la realización posterior del análisis molecular. Todos los tubos fueron correctamente cerrados y la tapa sellada con papel Parafilm para evitar intercambio de gases.

Estudio microbiológico por método semi-cuantitativo. Después de incubar los tubos por $48 \mathrm{~h}$ a $37^{\circ} \mathrm{C}$ en estufa de cultivo, las espátulas con las colonias adheridas de estreptococos del grupo mutans fueron observadas por transiluminación en un lente de magnificación de Spencer, para luego ser clasificadas de acuerdo al estándar recomendado por el método Linoscreen ${ }^{\circledR}$, de esta manera se agruparon según el recuento bacteriano en riesgo bajo (10.000 $50.000 \mathrm{UFC} / \mathrm{mL}$ ), moderado (100.000 - $250.000 \mathrm{UFC} / \mathrm{mL}$ ) $\mathrm{y}$ alto $(500.000-1.000 .000 \mathrm{UFC} / \mathrm{mL})$.

Extracción de ADN bacteriano. Para la extracción del ADN se centrifugó $1 \mathrm{~mL}$ de saliva a $13.400 \mathrm{rpm}$ por 15 minutos, se removió el sobrenadante, y al precipitado se le adicionó $200 \mathrm{uL}$ de buffer de lisis (Tris-HCl $10 \mathrm{mM}$, EDTA $1 \mathrm{mM}$, Tritón X-100 al 1\%, pH 8.0). Luego esta mezcla fue llevada a ebullición en baño María por 10 minutos, para luego ser centrifugada durante 5 minutos a $12.000 \mathrm{rpm}$, el nuevo sobrenadante fue recuperado y se le adicionó $500 \mathrm{uL}$ de isopropanol puro, siendo centrifugado nuevamente por 5 minutos a $12.000 \mathrm{rpm}$. Seguidamente, se eliminó el sobrenadante y se lavó el ADN extraído con 500 uL de isopropanol al $37 \%$ y se centrifugó a 12.000 rpm. Posteriormente, los tubos conteniendo el ADN bacteriano, se dejaron secar a temperatura ambiente, hasta la evaporación completa del alcohol y finalmente, el ADN fue resuspendido en $100 \mathrm{uL}$ de buffer TE (Tris-HCl $10 \mathrm{mM}$ y EDTA $1 \mathrm{mM}$, pH 8.0) y mantenidos $\mathrm{a}-20^{\circ} \mathrm{C}$.

Análisis molecular. Para la detección e identificación de las bacterias $S$. mutans y $S$. sobrinus, se procedió a amplificar un fragmento de ADN cromosomal mediante la técnica de Reacción en Cadena de la Polimerasa (PCR, Polymerase Chain Reaction), utilizando como templado: ADN cromosomal, saliva y saliva previamente hervida. La secuencia de los partidores utilizados es descrita en la Tabla I. 
Tabla 1. Secuencia de los partidores utilizados para la detección e identificación molecular de Streptococcus mutans y Streptococcus sobrinus en muestras de saliva por PCR.

\begin{tabular}{ccc}
\hline Primer & Secuencia & Localización cDNA \\
\hline SMUT5 & 5' - tga aac ctt gtc tat ctc ctc ttt acc -3' & $1.760-1.783$ \\
SMUT3 & 5'- tca gtt ttc aaa ggg ctc tg -3' & $1.877-1.896$ \\
SSOB5 & 5' - gca gtc tga cga tgc ttc tac -3' & $184-204$ \\
SSOB3 & 5'- ccg tca gtc caa caa ata atc -3' & $361-381$ \\
\hline
\end{tabular}

La secuencia de nucleótidos fue obtenida desde el GenBank, Número de acceso AE014854.1 para Streptococcus mutans y $\mathrm{N}^{\circ} \mathrm{AB} 083137.1$ para Streptococcus sobrinus.

El protocolo de PCR utilizado fue el siguiente: denaturación inicial por 3 minutos a $98^{\circ} \mathrm{C}$, seguido de 31 ciclos por 1 minuto a $95^{\circ} \mathrm{C}$ (denaturación), 1 minuto a $50^{\circ} \mathrm{C}$ para $S$. sobrinus y $53^{\circ} \mathrm{C}$ para $S$. mutans (hibridación), 1 minuto a $72^{\circ} \mathrm{C}$ (extensión), concluyendo con una extensión final a $72^{\circ} \mathrm{C}$ por 10 minutos. Los productos de PCR fueron evaluados por electroforesis en gel de agarosa al $2 \%$. Una vez finalizada la separación electroforética, los geles fueron teñidos con bromuro de etídio $(0,5 \mathrm{mg} / \mathrm{mL})$ y posteriormente visualizados en un transiluminador UV. La presencia de $S$. mutans fue identificada por un fragmento de 137 bp y de S. sobrinus por un fragmento de $198 \mathrm{bp}$.

Estudio de la especificidad de la amplificación por PCR. Debido a la no disponibilidad de cepas ATCC de $S$. mutans y $S$. sobrinus en nuestro laboratorio, para evaluar la especificidad de la metodología aquí propuesta, se recurrió al uso de enzimas de restricción, las cuales reconocen sitios específicos en el ADN, propios de cada especie bacteriana. Para confirmar la identificación de $S$. mutans y $S$. sobrinus se utilizaron las enzimas MboI (Fermentas, Lituania) y MspI (Amersham Biosciences, Suecia), respectivamente, siguiendo las instrucciones del fabricante. Los productos de restricción fueron sometidos a electroforesis en gel de agarosa al $2.0 \%$ por 40 minutos a $100 \mathrm{~V}$. Luego, los geles fueron teñidos con bromuro de etidio y visualizados en un transiluminador UV.

Análisis de la sensibilidad de la técnica de PCR. Para evaluar la sensibilidad de la técnica de PCR para la detección de $S$. mutans y S. sobrinus, se realizaron diluciones seriadas de muestras de saliva (que presentaban recuentos de 1.000.000 de UFC/ml determinados por el método Linoscreen ${ }^{\circledR}$ y PCR positiva para $S$. mutans o $S$. sobrinus, respectivamente) con agua destilada estéril, de forma de obtener concentraciones estimadas entre 1.000 a 1.000.000 de UFC/mL. Luego, $5 \mathrm{uL}$ de cada dilución fueron utilizados como templado en la técnica de PCR, utilizando las condiciones descritas anteriormente. Este análisis fue realizado por cuadriplicado.

Control de calidad del análisis molecular. La posibilidad de contaminación de los análisis moleculares fue excluida por la utilización de controles de reactivos en cada serie de amplificaciones. Además, en cada procedimiento se recurrió al uso de normas generales de bioseguridad. Es importante destacar también que todo el material y soluciones utilizadas fueron esterilizadas mediante el uso de autoclave; así mismo, la descontaminación del material mediante la exposición a luz UV antes y después de utilizarlo.

Análisis estadístico. El análisis estadístico se realizó con el uso del programa SigmaStat para Windows, versión 2.0 (EE.UU.). Inicialmente las variables continuas fueron evaluadas en forma descriptiva, se procedió al cálculo de promedio, desviaciones estándar y a la observación de valores máximos y mínimos.

\section{RESULTADOS}

1. Determinación del índice COPD. El índice COPD del grupo estudiado fue 3.59 \pm 2.96 , no existiendo diferencia significativas según sexo $(\mathrm{p}>0,05)$.

2. Recuento microbiológico y rango de riesgo de caries dental. Al determinar los recuentos de estreptococos del grupo mutans por el método semi-cuantitativo Linoscreen $®$, se observó que el 100\% de los escolares analizados presentaban estos microorganismos en su cavidad oral, con recuentos que variaban entre 10.000 a 1.000.000 UFC/mL.

De acuerdo a la clasificación de riesgo cariogénico, propuesta por Linossier et al. (2003), la cual está basada en el recuento de estreptococos del grupo mutans en saliva, se estableció que un $41.2 \%$ de los escolares estudiados presentaba bajo riesgo de caries dental, un $17.6 \%$ riesgo intermedio, y un $41.2 \%$ se encontraba en la categoría de alto riesgo (Tabla II).

\section{Detección e identificación de} Streptococcus por PCR. En las Figs. 1 y 2 se pueden observar los productos de amplificación de PCR para Streptococcus mutans y Streptococcus sobrinus con tamaños de 137 bp y 198 bp, respectivamente.

\subsection{Estudio de la especificidad de la téc-} nica de PCR. Para evaluar la especificidad de los primers utilizados se realizó la digestión de los fragmentos amplificados con endonucleasas de restricción que generaron fragmentos de DNA con tamaños específicos para cada especie. Al digerir el fragmento de 137 bp que identifica la presencia de $S$. mutans con la enzima de restricción $\mathrm{MboI}$, que reconoce la secuencia 5'--GATC-3', se obtuvieron fragmentos de 107 bp y 30 bp, lo que confirma la presencia de esta bacteria. De forma similar, al digerir el fragmento de 198 bp que identifica la presencia de $S$. sobrinus, con la endonucleasa $M s p I$, que reconoce el sitio $5^{\prime}-\mathrm{C}^{-} \mathrm{CGG}-3$, se obtuvieron los 
fragmentos de 81,75 y 42 bp. Los resultados de la digestión enzimática de $S$. sobrinus se pueden observar en la Fig. 3.

3.2. Estudio de la sensibilidad del PCR. Como ya se mencionó se realizaron diluciones seriadas de saliva, de forma de obtener concentraciones que variaron desde $1.000 \mathrm{a}$ 1.000.000 de UFC/mL. Luego de la realización de la técnica de PCR, fue posible detectar la presencia de ambas bacterias en concentraciones desde $1000 \mathrm{UFC} / \mathrm{ml}$. En las Figuras 4 y 5 se observan los resultados obtenidos para Streptococcus mutans y Streptococcus sobrinus, respectivamente.

3.3. Análisis de muestras clínicas mediante PCR. Se determinó que 47 de las 51 muestras de saliva fueron positivas, según la técnica de PCR, para las bacterias cariogénicas S. mutans y S. sobrinus, alcanzando un $92.1 \%$ de sensibilidad, al compararlo con el método microbiológico Linoscreen®.

En la Tabla III se puede observar que la frecuencia de $\mathrm{S}$. mutans en el grupo estudiado fue de un $88.2 \%$ (45/51) y de $11.8 \%$ (6/51) para S. sobrinus. La presencia de ambas bacterias fue detectada en 7.8\% (4/51) de los individuos estudiados. Al considerar las muestras que resultaron positivas, según el grado de riesgo cariogénico, se observó un $100 \%$ de prevalencia de estos microorganismos en el grupo con bajo riesgo, un $77.8 \%$ en el grupo con riesgo intermedio y $100 \%$ en el grupo con alto riesgo.

Tabla II. Rangos de riesgo de caries dental, según recuento de estreptococos del grupo mutans, obtenido por el método microbiológico Linoscreen $®$.

\begin{tabular}{lcc}
\hline Riesgo & Recuento microbiológico & $\boldsymbol{n}$ \\
\hline Bajo & $10.000-50.000 \mathrm{UFC} / \mathrm{mL}$ & 21 \\
Medio & $100.000-250.000 \mathrm{UFC} / \mathrm{mL}$ & 9 \\
Aalto & $500.000-1.000 .000 \mathrm{UFC} / \mathrm{mL}$ & 21 \\
\hline
\end{tabular}

$\mathrm{n}$, número de individuos

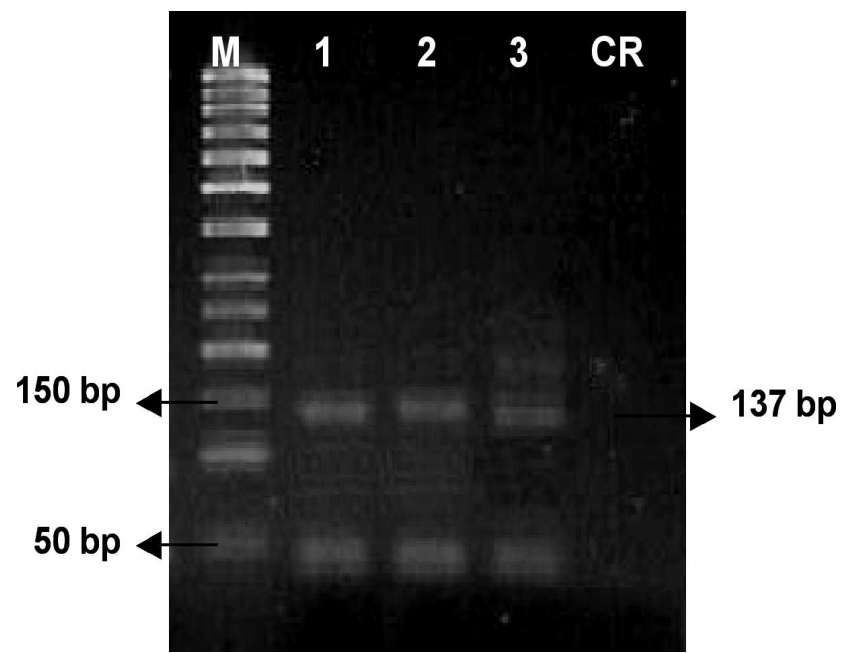

Fig. 1. Electroforesis en gel de agarosa al $2 \%$ teñido con bromuro de etidio mostrando el fragmento que identifica la presencia de Streptococcus mutans, amplificado directamente de saliva (Carril 1), saliva hervida (Carril 2) y ADN cromosomal (Carril 3). M, marcador de tamaño de $\mathrm{ADN}$ (50 bp), CR, control de reactivos.

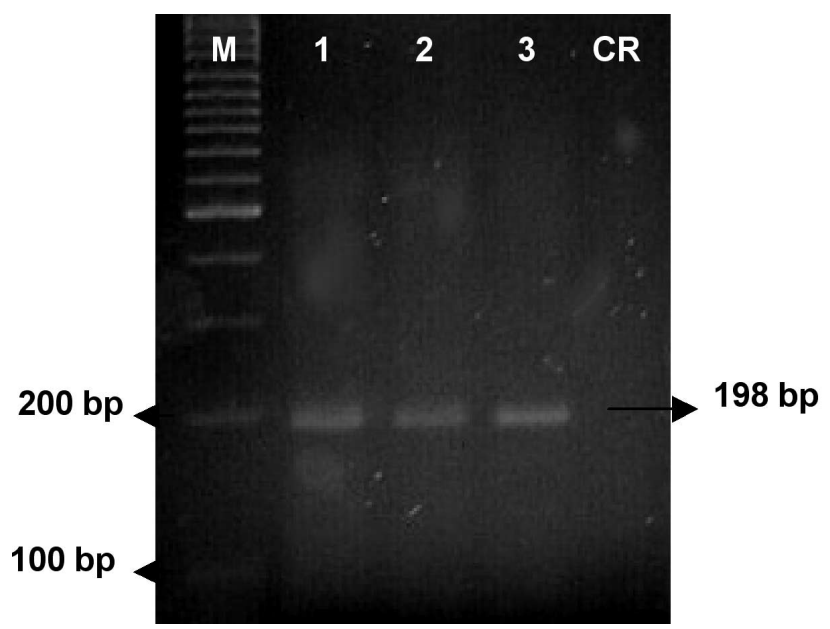

Fig. 2. Electroforesis en gel de agarosa al $2 \%$ teñido con bromuro de etidio mostrando el fragmento que identifica la presencia de Streptococcus sobrinus, amplificado de saliva (Carril 1), saliva hervida (Carril 2) y ADN cromosomal (Carril 3). M, marcador de tamaño de ADN (100bp), CR, control de reactivos.

Tabla III. Relación entre los rangos de riesgo cariogénico, obtenidos por método microbiológico y la detección obtenida por la técnica de PCR.

\begin{tabular}{cccccc}
\hline UFC/mL saliva & $\mathbf{n}$ & PCR (+) & PCR (+) & \multicolumn{1}{c}{ PCR (+) } & PCR (-) \\
S. grupo mutans & 21 & 16 & 1 & 2 & 2 \\
\hline $10.000-50.000$ & 9 & 6 & 1 & 0 & 2 \\
$100.000-250.000$ & 21 & 19 & 0 & 2 & 0 \\
$500.000-1.000 .000$ & 51 & 41 & 2 & 4 & 4 \\
\hline TOTAL & & S. mobrinus & & sobrinus & \\
\hline
\end{tabular}

n, número de individuos; PCR, reacción en cadena de la polimerasa. 


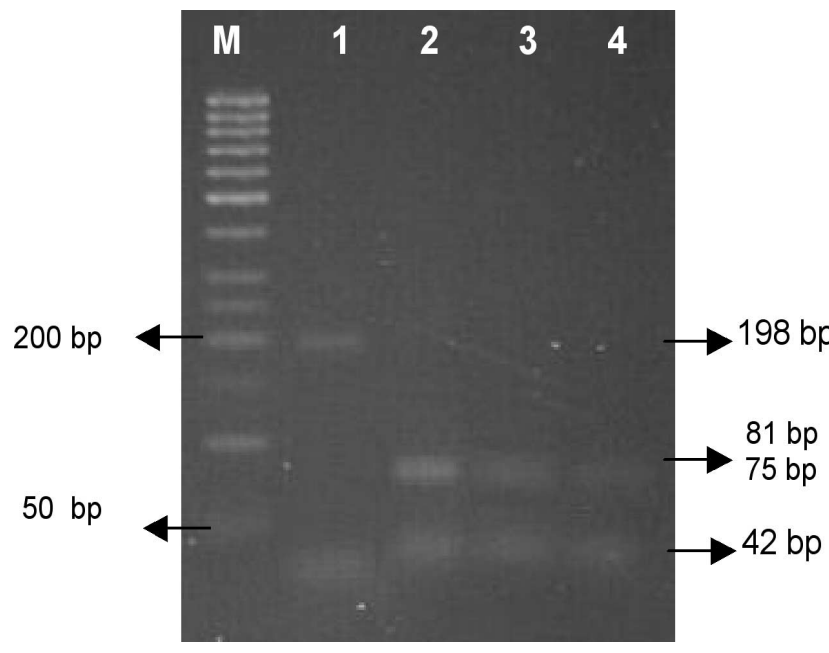

Fig. 3. Electroforesis en gel de agarosa al $2 \%$ teñido con bromuro de etidio para estudio de especificidad de S. sobrinus. Carril 1: Producto de PCR (198 bp). Carriles 2-4: Productos de PCR digeridos con la enzima MspI. M: marcador de $\operatorname{ADN}(50 \mathrm{bp})$.

\section{DISCUSIÓN}

Si bien en América Latina, la caries dental ha mostrado un descenso en los últimos 30 años en niños entre 5 y 13 años (Bönecker \& Cleaton-Jones, 2003) esta patología continúa teniendo una elevada prevalencia en niños y población general. Debido a esta situación es que el diagnóstico de bacterias con potencial cariogénico cobra relevancia al momento de plantearse estudios clínicos o epidemiológicos. Así, el presente estudio tuvo como objetivo implementar la metodología de PCR para la detección rápida de estreptococos cariogénicos en saliva.

Al analizar la situación de la salud dentaria de los individuos estudiados en este trabajo, según el índice COPD, ésta fue similar a la encontrada en otro estudio previo realizado en Chile (Linossier et al., 2003), y algo inferior a lo mostrado por el Estudio Nacional de Caries y Fluorosis realizado entre los años 1996 y 1999 (Linossier et al., 1999; Urbina et al., 1999).

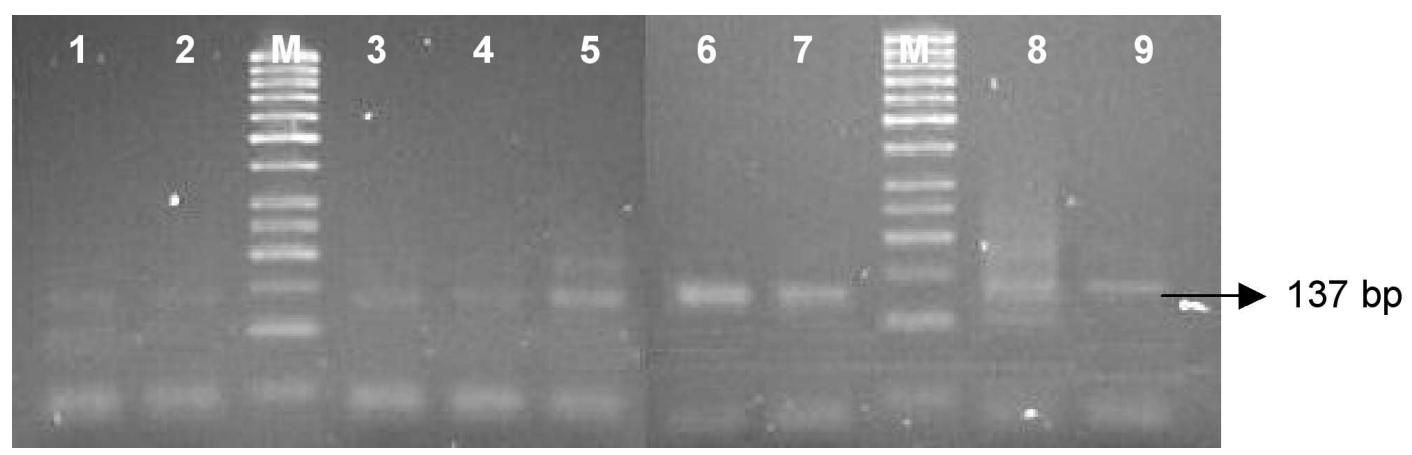

Fig. 4. Electroforesis en gel de agarosa al $2 \%$ teñido con bromuro de etidio para estudio de sensibilidad de Streptococcus mutans. Carril 1: $1.000 \mathrm{de} \mathrm{UFC} / \mathrm{mL}$, Carril 2: $10.000 \mathrm{UFC} / \mathrm{mL}$, Carril 3: $50.000 \mathrm{UFC} / \mathrm{mL}$, Carril 4: $100.000 \mathrm{UFC} /$ $\mathrm{mL}$, Carril 5: $150.000 \mathrm{UFC} / \mathrm{mL}$, Carril 6: $200.000 \mathrm{UFC} / \mathrm{mL}$, Carril 7: 250.000 UFC/mL, Carril 8: 500.000 UFC/mL, Carril 9: 1.000.000 UFC/mL. M: marcador de $\operatorname{ADN}$ (50 bp).

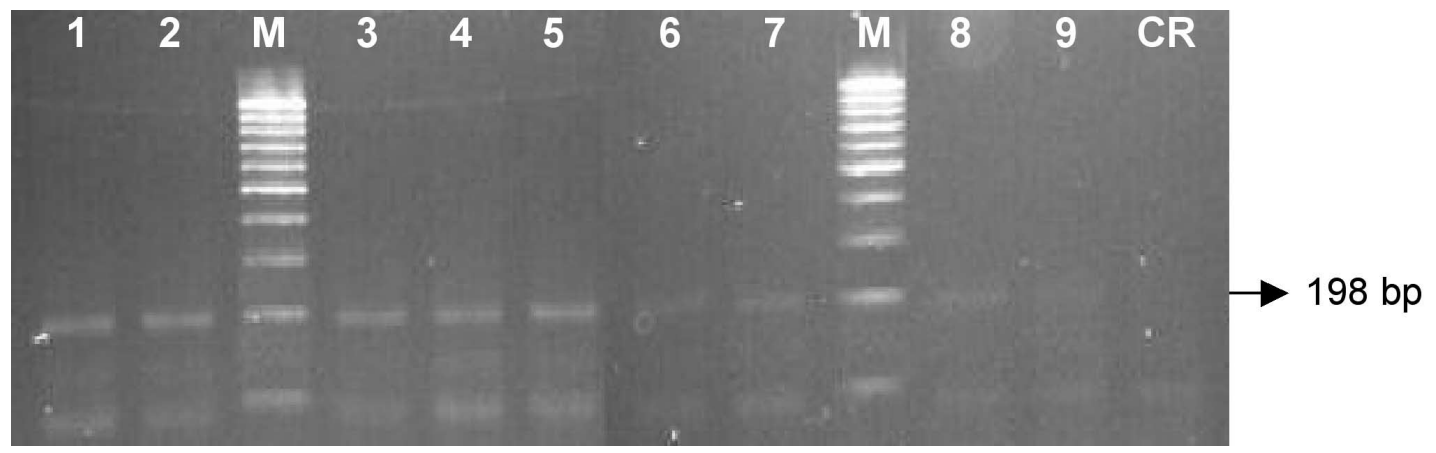

Fig. 5. Electroforesis en gel de agarosa al $2 \%$ teñido con bromuro de etidio para estudio de sensibilidad de Streptococcus sobrinus. Carril 1: 1.000 .000 de UFC/mL, Carril 2: 500.000 UFC/mL, Carril 3: 250.000 UFC/mL, Carril 4: 200.000 UFC/mL, Carril 5: 150.000 UFC/mL, Carril 6: 100.000 UFC/mL, Carril 7: 50.000 UFC/mL, Carril 8: 10.000 UFC/ mL, Carril 9: $1.000 \mathrm{UFC} / \mathrm{mL}$. M: marcador de ADN (100 bp), CR: control de reactivos. 
En relación a la prevalencia de los microorganismos estudiados, nuestra investigación mostró que el $100 \%$ de los niños estudiados son portadores de las bacterias estreptococos del grupo mutans, según el método microbiológico Linoscreen®. Siendo este resultado similar al observado en Chile, en mujeres embarazadas de las ciudades de Santiago (Villagrán et al., 1999) y Temuco (Herrera et al., 2007). Sin embargo, es mayor a la observada en estudios realizados en países como Australia y Estonia, donde se observó en niños menores de 4 años, la presencia de estreptococos del grupo mutans con una frecuencia de $80 \%$ y $58 \%$, respectivamente (Law \& Seow, 2007; Olak et al., 2007).

La frecuencia de las especies bacterianas identificadas en nuestro estudio, mediante la técnica de PCR, fueron de un $88,2 \%$ y $11,8 \%$ para $S$. mutans y $S$. sobrinus, respectivamente. Este resultado también es comparable al obtenido por Linossier et al. en el año 2003, quienes determinaron mediante serología una prevalencia de $84.0 \%$ y $6,0 \%$ para S. mutans y $S$. sobrinus en niños con edades entre los 2 y 6 años. Otros estudios muestran frecuencias que varían entre $51 \%$ y $100 \%$ para $S$. mutans, y entre $23 \%$ y $83 \%$ para $S$. sobrinus (Aguilera \& Estrada, 2003; Igarashi et al., 2000; Rodis et al., 2006; Okada et al., 2002; Okada et al., 2005). Es importante destacar que la variabilidad en los resultados podría deberse a diferencias en la sensibilidad del test, la metodología utilizada, la edad y origen de los individuos estudiados, entre otros factores.

Respecto del análisis de la sensibilidad, existen antecedentes que mencionan que las determinaciones moleculares son capaces de detectar hasta $100 \mathrm{fg}$ de ADN y 9 células lisadas (Igarashi et al., 2000). Este valor es muy cercano al obtenido en nuestros análisis, ya que se detectaron concentraciones de $1000 \mathrm{UFC} / \mathrm{ml}$, y dado que en los ensayos se utilizó como templado $5 \mu \mathrm{l}$ de saliva, nuestro límite de sensibilidad seria de 5 UFC. Otro estudio señala como limite de detección valores que varían, dependiendo del microorganismo estudiado, entre 1,5 y 5,5 pg de ADN (Hoshino et al., 2006), o bien dependiendo del gen utilizado para la identificación. Es así, como Matsuyama et al. (2005) observaron valores que variaron entre 10 y 100 pg para S. mutans y entre $100 \mathrm{fg}$ y $1 \mathrm{pg}$ para $S$. sobrinus cuando se analizaron los genes del RNAr 16s, glucosiltransferasa y dextranasa. Además, el mismo autor realizó un segundo PCR de los productos amplificados originalmente, mejorando de esta forma el límite de detección. Sin embargo, en esta metodología es necesario evaluar la posible aparición de resultados falsos positivos, lo que afectaría la utilidad de la técnica al verse reducida la especificidad de la misma, situación que fue demostrada por Al-Ahmad et al. (2006).

Contrastando la metodología microbiológica con la técnica molecular, en cuanto a la sensibilidad, tenemos que el método semi-cuantitativo Linoscreen ${ }^{\circledR}$ puede detectar desde 10.000 UFC/mL (Linossier et al., 2003), en tanto que la técnica de PCR utilizada en nuestro estudio fue capaz de amplificar los fragmentos que identifican las bacterias $S$. mutans y $S$. sobrinus, desde $1.000 \mathrm{UFC} / \mathrm{mL}$, demostrando que ésta metodología presenta una sensibilidad 10 veces mayor que el método microbiológico utilizado en nuestro estudio.

Sin embargo, otras metodologías, basadas en cultivos tradicionales, utilizadas para la cuantificación de estreptococos del grupo mutans tienen una sensibilidad similar a la de técnicas moleculares como el PCR en tiempo real (Real time-PCR). Ejemplo de esto, es la investigación realizada por Yano et al. (2002), quienes determinaron que la sensibilidad de la metodología de PCR en tiempo real es capaz de detectar 102 UFC por ml, valor similar a la sensibilidad del cultivo microbiológico que utiliza el medio MSB (Mitis-Salivarius-Bacitracina). No obstante, es necesario señalar que para ambas metodologías, la sensibilidad varía dependiendo del volumen de muestra aplicado a la placa de cultivo o a la mezcla de reacción de PCR.

La ausencia de amplificación en 4 de las 51 muestras analizadas que presentaban recuento microbiológico positivo para estreptococos del grupo mutans, puede deberse a la presencia de otras especies bacterianas pertenecientes a este grupo como $S$. downei, $S$. cricetus, $S$. rattus, $S$. ferus y $S$. macacae, las que no son posibles de detectar con los partidores utilizados, confirmando la elevada especificidad de la técnica de PCR.

Este estudio demuestra que es factible detectar bacterias cariogénicas directamente de muestras de saliva, y que además se pueden identificar $S$. mutans y $S$. sobrinus de forma rápida a partir de muestras clínicas, sin la necesidad de utilizar medios de cultivo, ya que los procedimientos tradicionales para la identificación de bacterias cariogénicas pueden demorar hasta una semana, a diferencia del PCR que puede tener resultados dentro de un día; situación que sin duda reporta beneficios para la realización de estudios clínicos y epidemiológicos.

Respecto de la utilidad en la clínica de la detección por la técnica de PCR aquí descrita, se podría discutir que el real aporte está en la cuantificación de las bacterias con potencial cariogénico, sin embargo, es importante recordar que la identificación de las especies bacterianas que están colonizando la cavidad oral también es relevante al evaluar el riesgo de un paciente para desarrollar caries, ya que no todas presentan el mismo potencial cariogénico y que la presencia de más de una de las especies de estreptococos del 
grupo mutans aumenta el riesgo para el desarrollo de caries (Hoshino et al., 2004). Es importante señalar también que la metodología implementada en este estudio permitiría la realización de análisis semicuantitativos, mediante la utilización de un estándar de ADN, con lo que se podrían obtener recuentos aproximados de las concentraciones de UFC de acuerdo a la intensidad de la señal de los amplicones generados.

De la misma forma, el beneficio de esta metodología en epidemiología radica en la posibilidad de identificar pobla- ciones de riesgo para el desarrollo de caries, permitiendo de esta forma generar evidencia para la implementación de las medidas correctivas adecuadas para la población estudiada.

En conclusión, podemos señalar que la metodología implementada en nuestro laboratorio nos permite la detección e identificación de $S$. mutans y $S$. sobrinus directamente a partir de muestras de saliva, y que ésta es una herramienta con un gran potencial para la realización tanto de análisis clínicos como epidemiológicos.

SAlAZAR, L. A.; VÁSQUEZ, C.; ALMUNA, A.; OPORTO, G.; SANTANA, R.; HERRERA, C. L. \& SANHUEZA, A. Molecular detection of cariogenic Streptococci in saliva. Int. J. Morphol., 26(4):951-958, 2008.

SUMMARY: Streptococcus mutans and Streptococcus sobrinus are the main causative organisms of dental caries. Nevertheless, the microbiological and biochemical methods, available at the moment in Chile, do not allow to the fast detection and identification of these bacteria. The aim of this investigation is implement the polymerase chain reaction (PCR) technique to detect the presence of $S$. mutans and S. sobrinus in saliva. A total of 51 schoolchildren (5 to 17 years old) from five different schools from Temuco city (Chile) participated in this study. The presence of salivary mutans streptococci was determined by microbiological method, and the species differentiation was assessed using PCR technique. The sensitivity for the PCR technique was $1000 \mathrm{cfu} / \mathrm{mL}$ of saliva, ten times superior to the sensitivity of the microbiological method used $(10,000 \mathrm{cfu} / \mathrm{mL})$. In addition, the analysis of the specificity of the amplification, evaluated by enzymatic restriction, confirmed the presence of the investigated bacteria. The prevalence of $S$. mutans was of $88.2 \%$ and for $S$. sobrinus was $11.8 \%$. The combined presence of both bacteria was observed in $7.8 \%$ of the individuals. In conclusion, the obtained results indicate that the implemented methodology is useful for the rapid detection of S. mutans and S. sobrinus in saliva.

KEY WORDS: Caries; Streptococcus mutans; PCR.

\section{REFERENCIAS BIBLIOGRÁFICAS}

Aguilera, L. \& Estrada, I. Detección de una secuencia del gen spaP de Streptococcus mutans en muestras de placa dental mediante reacción en cadena de la polimerasa (PCR). Revista ADM., 60:180-4, 2003.

Al-Ahmad, A.; Auschill, T. M.; Braun, G.; Hellwig, E. \& Arweiler, N. B. Overestimation of Streptococcus mutans prevalence by nested PCR detection of the 16S rRNA gene. J. Med. Microbiol., 55:109-13, 2006.

Bönecker, M. \& Cleaton-Jones, P. Trends in dental caries in Latin American and Caribbean 5-6- and 11-13-year-old children: a systematic review. Community. Dent. Oral. Epidemiol., 31:152-7, 2003.

Herrera, C.L.; Pantoja, P.; de La Maza, T.; Sanhueza, A. \& Salazar, L.A. Diagnóstico microbiológico y molecular de bacterias cariogénicas en mujeres embarazadas de la Región de La Araucanía, Chile. Rev. Chil. Infectol. 24:270-5, 2007.

Hildebrandt, G.H. \& Bretz, W.A. Comparison of culture media and chairside assays for enumerating mutans streptococci. J. Appl. Microbiol., 100:1339-47, 2006.
Hoshino, T.; Kawaguchi, M.; Shimizu, N.; Hoshino, N.; Ooshima T. \& Fujiwara T. PCR detection and identification of oral streptococci in saliva samples using gtf genes. Diagn. Microbiol. Infect. Dis., 48:1959, 2004

Igarashi, T.; Yamamoto, A. \& Goto, N. PCR for detection and identification of Streptococcus sobrinus. J. Med. Microbiol., 49:1069-74, 2000.

Law, V. \& Seow, W.K. Townsend G. Factors influencing oral colonization of mutans streptococci in young children. Aust. Dent. J., 52:93-100, 2007.

Lindquist, B. \& Emilson C.G. Colonization of Streptococcus mutans and Streptococcus sobrinus genotypes and caries development in children to mothers harboring both species. Caries. Res., 38:95103, 2004.

Linossier, A.; Carvajal, P.; Donoso, E. \& Orrego, M. Fluorosis dental: recuento de Streptococcus mutans en escolares provenientes de la Primera Región de Chile. Estudio longitudinal. Rev. Med. Chile, 127:1462-8, 1999. 
SALAZAR, L. A.; VÁSQUEZ, C.; ALMUNA, A.; OPORTO, G.; SANTANA, R.; HERRERA, C. L. \& SANHUEZA, A. Detección molecular de estreptococos cariogénicos en saliva. Int. J. Morphol., 26(4):951-958, 2008.

Linossier, A.; Vargas, A.; Zillmann, G.; Arriagada, M.; Rojas, R. \& Villegas, R. Streptococci mutans: a semiquantitative method to assess the risk to oral infection in preschool Chilean children. Rev. Med. Chil., 131:412-8, 2003.

Matsuyama, J.; Sato, T.; Washio, J.; Mayanagi, G.; Ito, Y.; Abiko, Y. et al. PCR for detection of mutans streptococci in human dental plaque. International. Congress. Series. 1284:158-62, 2005.

Napimoga, M.H.; Höfling, J.F.; Klein, M.I.; Kamiya, R.U. \& Gonçalves RB. Transmission, diversity and virulence factors of Sreptococcus mutans genotypes. J. Oral. Sci., 47:59-4, 2005.

Oho, T.; Yamashita, Y.; Shimazaki, Y.; Kushiyama, M. \& Koga T. Simple and rapid detection of Streptococcus mutans and Streptococcus sobrinus in human saliva by polymerase chain reaction. Oral. Microbiol. Immunol., 15:258-62, 2000.

Okada, M.; Soda, Y.; Hayashi, F; Doi, T.; Suzuki, J.; Miura, K. et al. PCR detection of Streptococcus mutans and S. sobrinus in dental plaque samples from Japanese preschool children. J. Med. Microbiol., 51:443-7, 2002.

Okada, M.; Soda, Y.; Hayashi, F; Doi, T.; Suzuki, J.; Miura, K.; et al. Longitudinal study of dental caries incidence associated with Streptococcus mutans and Streptococcus sobrinus in pre-school children. J. Med. Microbiol. 54:661-5, 2005.

Olak, J.; Mändar, R.; Karjalainen, S.; Söderling, E. \& Saag, M. Dental health and oral mutans streptococci in 2-4year-old Estonian children. Int. J. Paediatr. Dent., 17:927, 2007.

Rodis, O.M.; Shimono, T.; Matsumura, S.; Hatomoto, K.; Matsuo, K.; Kariya, N. et al. Cariogenic bacteria and caries risk in elderly Japanese aged 80 and older with at least 20 teeth. J. Am. Geriatr. Soc., 54:1573-7, 2006.

Sato, T.; Matsuyama, J.; Kumagai, T.; Mayanagi, G.; Yamaura, M.; Washio, J. et al. Nested PCR for detection of mutans streptococci in dental plaque. Lett. Appl. Microbiol., 37:66-9, 2003.

Selwitz, R.H.; Ismail, A.I. \& Pitts, N.B. Dental Caries. Lancet, 369:51-9, 2007.

Urbina, T.; Caro, J.P. \& Vicent, M. Caries y Fluorosis en Niños de 6 a 8 años y 12 años Minsal, Chile. Departa- mento de Estadísticas e Información. 1996-1999.

Villagrán, E.; Linossier, A. \& Donoso, E. Count of salivary Streptococci mutans in pregnant women of the metropolitan region of Chile: cross-sectional study. Rev. Med. Chile, 127:165-70, 1999.

Yano, A.; Kaneko, N.; Ida, H.; Yamaguchi, T. \& Hanada N. Real-time PCR for quantification of Streptococcus mutans. FEMS Microbiol. Lett., 217:23-30, 2002.

Dirección para correspondencia:

Prof. Dr. Luis Antonio Salazar

Departamento de Ciencias Básicas,

Facultad de Medicina

Universidad de La Frontera

Av. Francisco Salazar 01145

Casilla 54-D

Temuco

CHILE

Tel.: +56 45592895

Fax: +56 45592831

Email: Isalazar@ufro.cl

Recibido : 22-07-2008

Aceptado: 21-09-2008 